\title{
Ultrasonic Powder Consolidation of Sn/In Nanosolder Particles and Their Application to Low Temperature Cu-Cu Joining
}

\author{
Yang Shu, ${ }^{1}$ Somayeh Gheybi Hashemabad, ${ }^{2}$ Teiichi Ando, ${ }^{2}$ and Zhiyong Gu ${ }^{1, *}$ \\ 1. Department of Chemical Engineering \\ University of Massachusetts Lowell \\ One University Ave \\ Lowell, MA 01854, USA
}

2. Department of Mechanical and Industrial Engineering

Northeastern University

360 Huntington Avenue

Boston, MA 02115, USA

* Corresponding author:

Phone: (978) 934-3540

Fax: (978) 934-3047

E-mail: Zhiyong_Gu@uml.edu 


\begin{abstract}
Tin/Indium ( $\mathrm{Sn} / \mathrm{In})$ nanosolder particles in the size range of 40-70 $\mathrm{nm}$ were successfully consolidated into nanosolder films by the ultrasonic power consolidation (UPC) method. The consolidated nanosolder film prevents the nanoparticles from oxidation, which is a common problem of nanomaterials during storage and processing, and makes the nanoparticles easier to handle. The quality of the consolidated nanosolders was examined by scanning electron microscopy (SEM), X-ray diffraction (XRD), and differential scanning calorimetry (DSC). The consolidated $\mathrm{Sn} / \mathrm{In}$ nanosolder films were then used to join copper $(\mathrm{Cu})$ plates at two soldering conditions (high pressure vs. low pressure). SEM and energy dispersive X-ray spectroscopy (EDS) were used to study the intermetallic compound (IMC) formation and growth during thermal aging. The IMC layer consisted of $\eta_{-} \mathrm{Cu}_{6}(\mathrm{Sn}, \mathrm{In})_{5}$ and no $\mathrm{Cu}_{3}(\mathrm{Sn}, \mathrm{In})$ was observed. The thickness of the IMC layer followed a linear relationship with the square root of the aging time, indicating diffusion controlled kinetics. The results indicated that pressure is critical for effective $\mathrm{Cu}-\mathrm{Cu}$ joining by limiting the IMC growth. Finally, pull tests of the specimen joined by the consolidated nanosolder film under high pressure showed a comparable result with the solder joints formed by $\mathrm{Sn} / \mathrm{In}$ solders reported in literature.
\end{abstract}

Keywords: Ultrasonic Powder Consolidation (UPC); Sn/In nanosolder; low temperature soldering; $\mathrm{Cu} / \mathrm{Cu}$ joining; intermetallic growth; thermal aging; mechanical properties. 


\section{Introduction}

Joining is one of the key processes in manufacturing and repairing. It can be achieved by a variety of methods such as welding, soldering, brazing, adhesive bonding, and diffusion bonding [1-2]. Fusion welding, normally performed under relatively high temperature, tends to have negative effects on the microstructure and properties of the weld. Unlike fusion welding, soldering, brazing, and adhesion involve lower temperatures with fewer side effects. [3]

The soldering process aims to join two or more metal working pieces together by melting and flowing a filler metal (solder) between the working pieces. It has been widely used in plumbing, metalwork, jewelry, and electronics. Nowadays, low temperature solder materials have a large demand in electronics industry [4]. To reduce the cost, many inexpensive components and circuit board materials such as polymer capacitors and film capacitors are being implemented in the products by many electronics manufacturers. However, this practice often introduces manufacturing yield problems because those materials (such as polymer materials) tend to be more sensitive to high temperature (e.g., $>200{ }^{\circ} \mathrm{C}$ ). So low temperature solders (e.g., in the temperature of $50-183{ }^{\circ} \mathrm{C}$ ) are desired to assemble those temperature sensitive components during surface mount assembly [5-6]. On the other hand, flexible electronics can have many applications, such as flexible screen displays and stretchy sensing tools. The flexibility of these types of electronics depends on the polymer based substrate [7-17]. To assemble electronic components on the polymer substrate, one must use a limited heating process because the polymer substrates usually are not resistant to high temperature. Therefore, for flexible

electronics assembly, low processing temperature solder materials are also required in order to prevent the polymer substrate from being damaged.

Most of the solder materials that meet the requirement of low melting temperatures are bismuth (Bi) or indium (In) based alloys [18-26]. Among the low melting temperature solders, 34Sn$43 \mathrm{~Pb}-14 \mathrm{Bi}, 58 \mathrm{Bi}-42 \mathrm{Sn}$, and $40 \mathrm{Sn}-40 \mathrm{In}-20 \mathrm{~Pb}$ are the relatively popular ones [26]. However, some of these solders are not favored due to the toxicity of lead. In-based solders normally have very low melting temperatures (lower than Bi-based solders), and are soft and ductile [26]. Also, In has been reported to have a good wettability on both metallic and non-metallic surfaces [26]. 
Ultrasonic powder consolidated (UPC) is a new additive manufacturing technique in which powders are metallurgically consolidated by the action of ultrasonic vibration at low to moderate temperatures, typically within a second [27]. It would be a very efficient way to more easily handle the nanomaterials and prevent the surface oxidation (a common problem of nanomaterials) [28-30]. In this work, $\mathrm{Sn} / \mathrm{In}$ nanosolder particles were consolidated into $\mathrm{Sn} / \mathrm{In}$ nanosolder films by UPC. To test the consolidated $\mathrm{Sn} / \mathrm{In}$ nanosolders for soldering, a copper-copper $(\mathrm{Cu}-\mathrm{Cu})$ joining system was selected. Two joining methods (high pressure vs. low pressure) were applied to compare the joining condition in the $\mathrm{Cu}-\mathrm{Cu}$ system. The intermetallic compound (IMC) formation and growth during aging were studied to examine the joint quality. Finally, pull tests were conducted to investigate the mechanical property of the solder joint formed by UPC consolidated Sn/In nanosolder film.

\section{Experiments}

\subsection{Materials and chemicals used}

Sodium dodecyl sulfate (SDS) (85\%) and ethanol (anhydrous) were purchased from Fisher Scientific. Tin (II) sulfate $\left(\mathrm{SnSO}_{4}, 99 \%\right)$, indium chloride $\left(\mathrm{InCl}_{3}, 99.995 \%\right)$ and Sodium borohydride $\left(\mathrm{NaBH}_{4}, 99 \%\right)$ were purchased from Acros Organics. Hydrochloric acid $(\mathrm{HCl}$, 36.5\%-38\%) was obtained from VWR scientific. DI water was obtained from a Barnstead Nanopure water purification system. All materials were used without further purification. $\mathrm{Cu}$ plates (ASTM-B152, $0.53 \mathrm{~mm}$ thickness) purchased from Small Parts Incorporated were used for joining tests. Stay-clean Flux was purchased from Harris Products Group and used without further treatment; the main compositions of the Flux include ammonium chloride, zinc chloride, hydrochloric acid, and methanol. Castamount acrylic hardener and acrylic powder from Pace Technology were used to mount the samples for cross-section analysis. $0.05 \mu \mathrm{m}$ alumina polishing particles (Pace Technology) were used to polish the mounted samples.

\subsection{Synthesis of $\mathrm{Sn} / \mathrm{In}$ nanosolder particles}

A composition close to the eutectic Sn/In alloy nanosolder, Sn/In 50/50, was selected in this study. Sn/In nanosolder particles were synthesized through a surfactant assisted one-step chemical reduction method [31]. Firstly, SDS was added into DI water to form a $8 \mathrm{mM}$ solution. 
Then $\mathrm{HCl}$ was added to adjust the $\mathrm{pH}$ from 7 to around 2.7 before dissolving the metal precursors of $\mathrm{SnSO}_{4}$ and $\mathrm{InCl}_{3}$ solutions. After that, an excess amount of $\mathrm{NaBH}_{4}$ solution was added into the system through a syringe pump (single-syringe infusion pump, KDS LEGATO $110, \mathrm{KD}$ Scientific) at a constant speed of $20 \mathrm{~mL} / \mathrm{h}$. Then the reaction was continued for $30 \mathrm{~min}$ at room temperature. The resulting samples were centrifuged (5804 Centrifuge, Eppendorf) at 7000 RPM and washed 5 times with DI water and 3 times with ethanol through dispersion and centrifuge cycles.

\subsection{UPC consolidation}

The $\mathrm{Sn} / \mathrm{In}$ nanosolder particles were ultrasonically consolidated as shown schematically in Fig. 1. A STAPLA Condor ultrasonic welder operated at $3 \mathrm{~kW}$, fixed frequency of $20 \mathrm{kHz}$ and adjustable vibration amplitude of up to $9 \mu \mathrm{m}$ at the sonotrode tip was employed in the UPC setup. The samples were consolidated using a die-punch arrangement as illustrated in Fig. 1. The die and the punch were made of stainless steel and had a matching diameter of $4.1 \mathrm{~mm}$. About $0.08 \mathrm{~g}$ of $\mathrm{Sn} / \mathrm{In}$ nanosolder particles (powders) was placed in the die and held under a pressure of 100 MPa applied through the sonotrode and the punch. Then in-plane ultrasonic vibration was applied to the powder compact for $1 \mathrm{~s}$ while the powder was kept under $100 \mathrm{MPa}$. Three temperatures (room temperature, $50^{\circ} \mathrm{C}$ and $70{ }^{\circ} \mathrm{C}$ ) were tested to determine the best condition of consolidation. The consolidated specimens were at $4 \mathrm{~mm}$ in diameter and $1-1.2 \mathrm{~mm}$ in thickness, and about $0.06-0.07 \mathrm{~g}$ in mass. The mass difference before and after the consolidation was accounted for by the residue on the die. For cross-section observation, the consolidated nanosolder film was first mounted in the acrylic mounting material, then polished by sand papers with different grit sizes (from 120 to 1200) and finally polished by alumina polishing particles. 


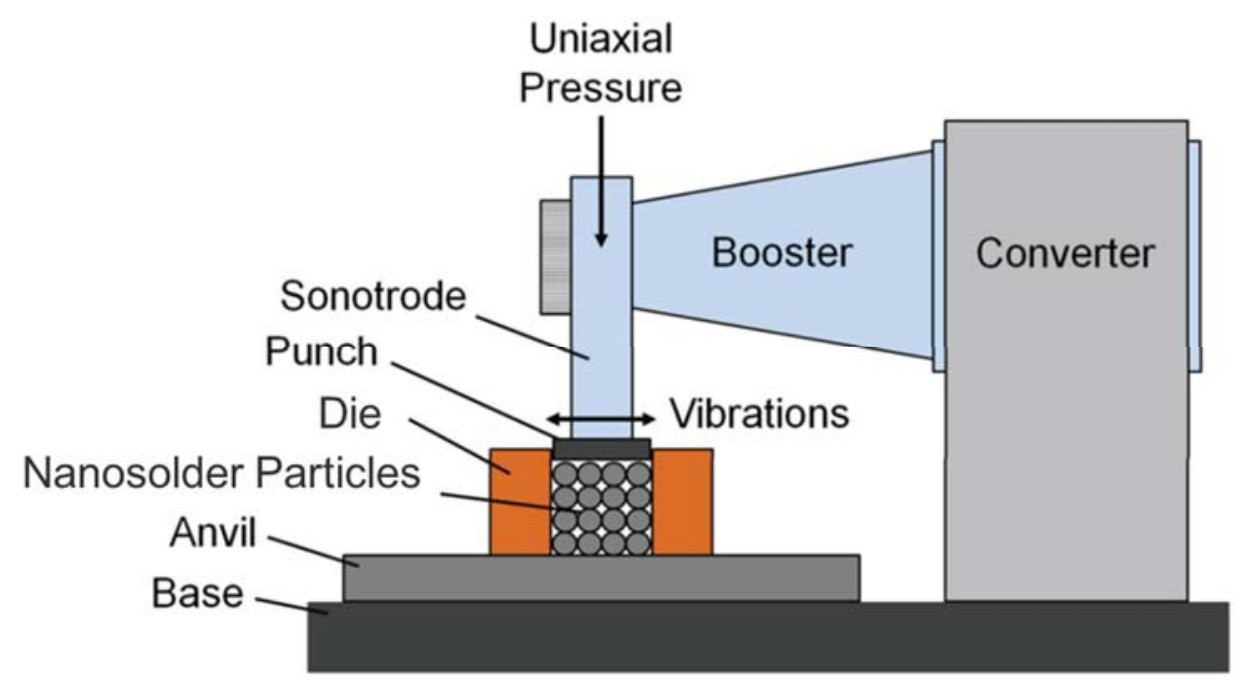

Fig. 1: Scheme of the UPC setup

\section{$2.4 \quad \mathrm{Cu}-\mathrm{Cu}$ joining experiments}

Copper-copper $(\mathrm{Cu}-\mathrm{Cu})$ joining has many applications in industry such as electronics, roofing, plumbing, and industrial machinery [31]. Here, two methods were studied to join two $\mathrm{Cu}$ plates (each about $20 \mathrm{~mm} \times 10 \mathrm{~mm} \times 0.56 \mathrm{~mm}$ ) together using the consolidated $\mathrm{Sn} / \mathrm{In}$ nanosolder films. Under both conditions, the $\mathrm{Cu}$ plates were rinsed with diluted nitric acid ( $\mathrm{pH} 3-4)$ and followed by DI water before use. A consolidated $\mathrm{Sn} / \mathrm{In}$ nanosolder film was placed between two $\mathrm{Cu}$ plates with $5 \mu \mathrm{L}$ of flux on each side to form a sandwich structure. Two heating conditions were tested. In the first condition (method I), the heating of the sandwich structure was done in an argon bath, under a constant pressure of $100 \mathrm{MPa}$ using the UPC setup as shown in Fig. 1. The sandwich structure was placed between the sonotrode and the anvil, then heated up to $150{ }^{\circ} \mathrm{C}$ and kept at $150{ }^{\circ} \mathrm{C}$ for $5 \mathrm{~min}$ (so called dwell time). After that, the sample was cooled down to room temperature, which was ready for the following testing. To compare the pressure and dwell time effects, a low pressure joining method (method II) was also utilized. A programmable tube furnace (Lindberg/Blue M, Thermal Scientific) was used for the low pressure joining. The sandwich structure, secured by a C clamp screw compressor, was placed in the furnace and sealed in argon environment. First, the tube temperature was increased to about $90{ }^{\circ} \mathrm{C}$ from room temperature $\left(\sim 25^{\circ} \mathrm{C}\right)$ in a time duration of $10 \mathrm{~min}$ as the pre-heating step. Then, the temperature was increased to $100{ }^{\circ} \mathrm{C}$ in $1 \mathrm{~min}$ as the soak step. After that, the temperature was increased to the peak temperature of $150{ }^{\circ} \mathrm{C}$ and kept at $150{ }^{\circ} \mathrm{C}$ for dwell times of $5 \mathrm{~min}, 15 \mathrm{~min}$, and $30 \mathrm{~min}$, 
respectively. A cooling step ( $\sim 5 \mathrm{~min}$ through natural cooling) was followed to cool down the samples to the room temperature.

\subsection{Aging tests}

To study the formation of intermetallic compounds (IMC) and interfacial microstructure change over time, a series of aging tests were performed on the specimens that were joined by the two methods as discussed above. After the joints were formed, the samples were kept in the tube furnace for extended periods of $50 \mathrm{~h}$ and $100 \mathrm{~h}$, respectively, at $100{ }^{\circ} \mathrm{C}$. Then the samples were cooled down to room temperature and polished for cross-section study under SEM.

\subsection{Metallographic characterization and tensile tests}

A JEOL7401F field emission-scanning electron microscope (FE-SEM) and a Philips EM400 transmission electron microscopy (TEM) were used to examine the morphology of the assynthesized $\mathrm{Sn} / \mathrm{In}$ nanosolder particles. The nanosolder suspension was dropped on a conductive silicon wafer which was attached onto a sample stub by carbon tape for SEM observation. The samples were then dried for SEM imaging. To study the microsctructure of the consolidated nanosolder film, the specimen was mounted in epoxy and polished using a cross-section polisher (Pace technology NANO 1000T grinder-polisher). Then the polished sample was examined by SEM. Energy dispersive X-ray spectrometer (EDS) equipped on the FE-SEM was used to analyze the chemical composition of the solder joint. Here, the chemical composition was taken as the average of three analysis points of the sample. X-ray diffraction (XRD, BRUKER AXS D5005 X-ray diffractometer, $\mathrm{Cu} \mathrm{K \alpha}$ radiation, $\lambda=1.540598 \AA$ ) was used to determine the structure of the consolidated nanosolder films. The melting point of the consolidated nanosolder films was measured by differential scanning calorimetry (DSC, TA Instrument Q100). SEM images were analyzed by ImageJ to measure the porosity of the solder joint. Pull tests were performed on Instron (Instron 4466) with a constant crosshead speed of $1 \mathrm{~mm} / \mathrm{min}$ along the vertical direction of the sandwich structure at room temperature. The tensile force $\mathrm{F}$ and displacement $d$ were recorded. The tensile stress of the specimen was calculated as $F / \pi R^{2}$ where $\mathrm{R}$ is the radius of the consolidated $\mathrm{Sn} / \mathrm{In}$ nanosolder film (after reflow). The maximum value of $\mathrm{F} / \pi \mathrm{R}^{2}$ of the stress-displacement curve where the failure occurred was used as the joint strength of the specimen. 


\section{Results and discussion}

\subsection{Sn/In nanosolder particle formation}

The SEM and TEM images of the Sn/In 50/50 nanosolder particles for UPC are shown in Fig. 2. The particles are spherical and in a size range of 40-70 nm. The mass ratio of $\mathrm{Sn} / \mathrm{In} / \mathrm{O}$ measured from EDS was 45/50.4/4.6, where the small amount of $\mathrm{O}$ was from the water based synthesis process. A thin layer of Sn/In oxide may be formed on the surface of the nanosolder particles. The crystalline structure and melting point were measured by XRD and DSC, respectively. The crystalline structure was determined to be mainly $\mathrm{InSn}_{4}$ with some In, whereas the peak on DSC at $116.1{ }^{\circ} \mathrm{C}$ was due to the eutectic melting of $\mathrm{InSn}_{4}$ and In. More details will be discussed in Section 3.2 .
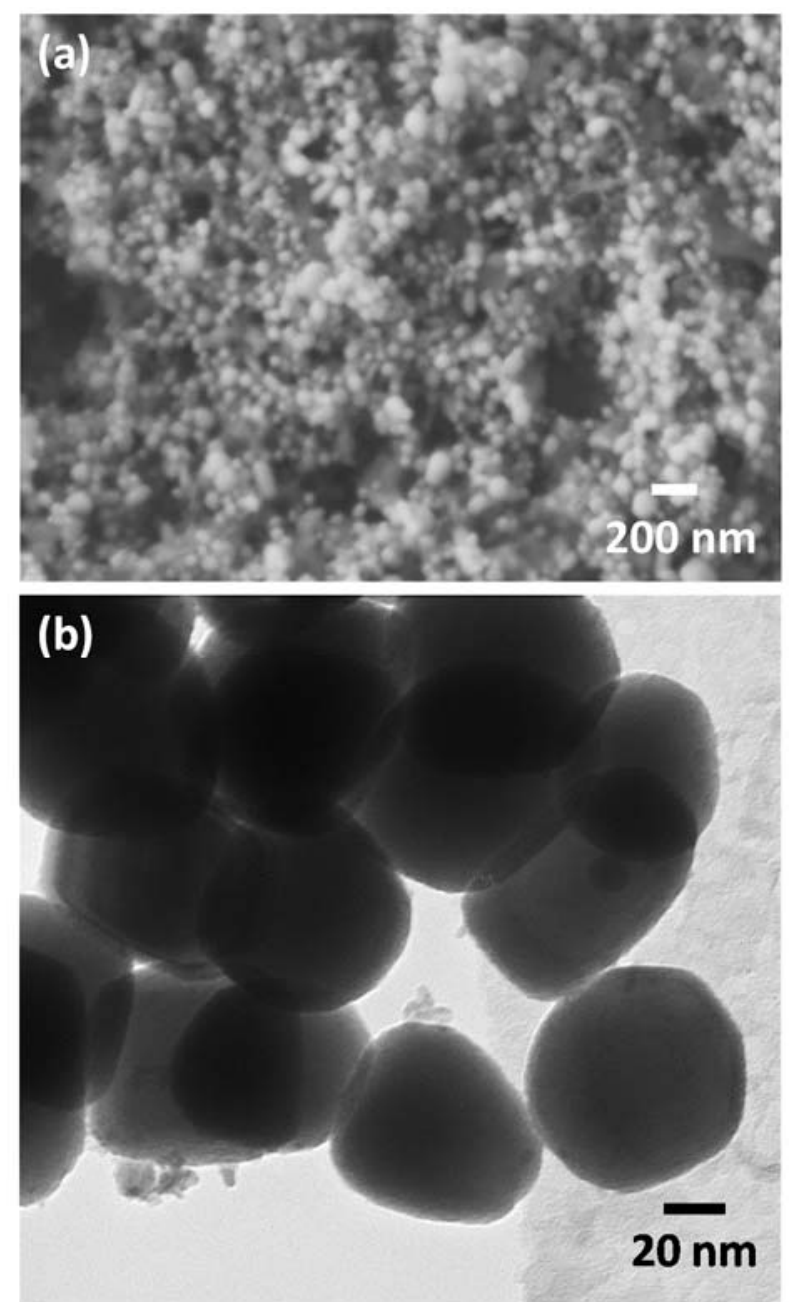

Fig. 2: Electron microscopic images of Sn/In nanosolder particles: (a) SEM, (b) TEM. 


\subsection{Characterization of consolidated $\mathrm{Sn} / \mathrm{In}$ nanosolder films}

Fig. 3 shows an SEM image of the cross section of a consolidated specimen of $\mathrm{Sn} / \mathrm{In} 50 / 50$ nanosolders. The consolidation was done at room temperature without protective atmosphere. From the cross section of the consolidated nanosolder film, the nanoparticles all seem to be consolidated into a fully densified structure with metallurgical integrity and no porosity. The samples consolidated at $50{ }^{\circ} \mathrm{C}$ and $70{ }^{\circ} \mathrm{C}$ had a fully densified structure as well. However, room temperature was sufficient to produce full densification, and thus there is no need to consolidate the nanoparticles at $50{ }^{\circ} \mathrm{C}$ or above. Therefore, room temperature consolidation was used for the following tests in this study.

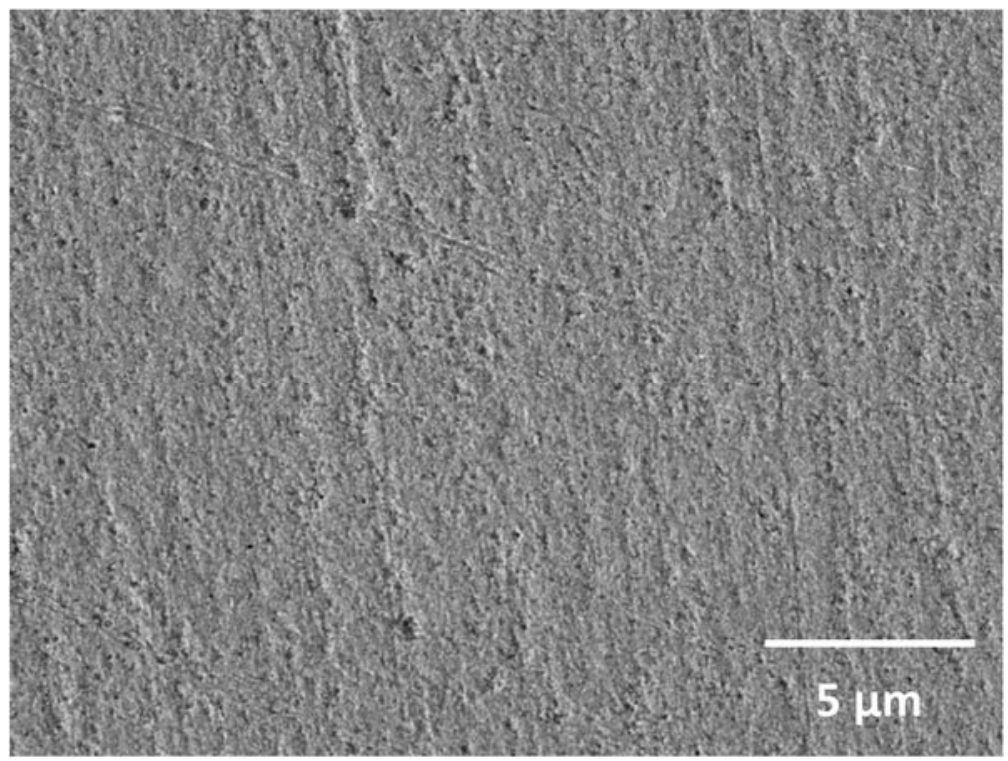

Fig. 3: SEM image of the cross section of Sn/In 50/50 nanosolder film consolidated at room temperature.

Fig. 4 shows the EDS results of the $\mathrm{Sn} / \mathrm{In}$ nanosolder film consolidated at room temperature. The mass percentage ratio of $\mathrm{Sn} / \mathrm{In} / \mathrm{O}$ is $44.2 / 49.6 / 6.1$, which is very close to the value of $\mathrm{Sn} / \mathrm{In}$ nanosolder particles before the consolidation ( $\mathrm{Sn} / \mathrm{In} / \mathrm{O}: 45 / 50.4 / 4.6)$. The elemental composition also compared well to the result of the previous study on $\mathrm{Sn} / \mathrm{In}$ nanosolder synthesis [32]. Thus, the elemental composition remained the same through the UPC process, and no significant oxidation occurred. The structural information of the nanosolders before and after consolidation was shown in Fig. 5. In both XRD spectra before and after the consolidation, the specimens were 
consisted of $\mathrm{InSn}_{4}$ and In. No phase change or new phase formation occurred during the consolidation. Therefore, the crystalline structure of the nanosolder did not change throughout the consolidation. The consistency of the crystalline structure was verified by DSC. Fig. 6 showed the DSC comparison of the nanosolder particles and consolidated nanosolder films. An endothermic peak at around $116^{\circ} \mathrm{C}$ from the eutectic melting between $\mathrm{InSn}_{4}$ and In was observed in both plots. The small difference $\left(0.7^{\circ} \mathrm{C}\right)$ of the peak temperatures indicated that the phase transition temperature also remained the same after the consolidation [32]. From the EDS, XRD, and DSC analysis, the nanosolders retained the same properties of elemental composition, crystal structure, and melting temperature from the originally dispersed particles throughout the consolidation, except that they were fully consolidated into a film.

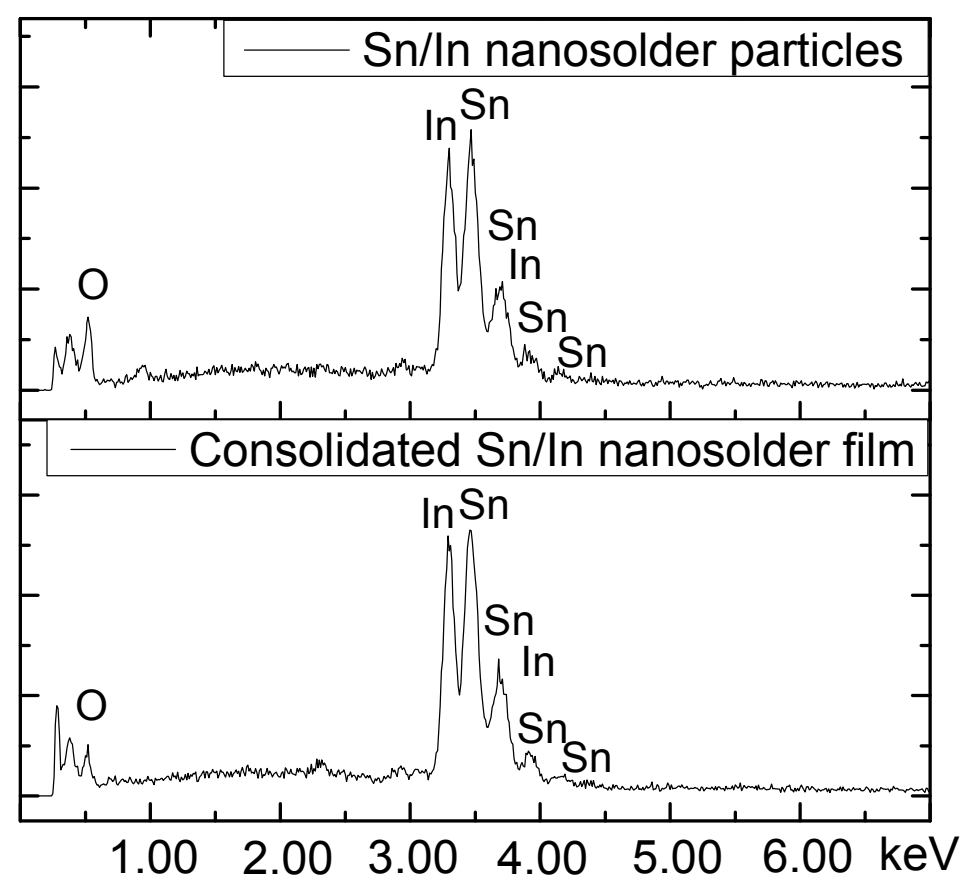

Fig. 4: EDS spectra of the nanosolders before and after consolidation. 


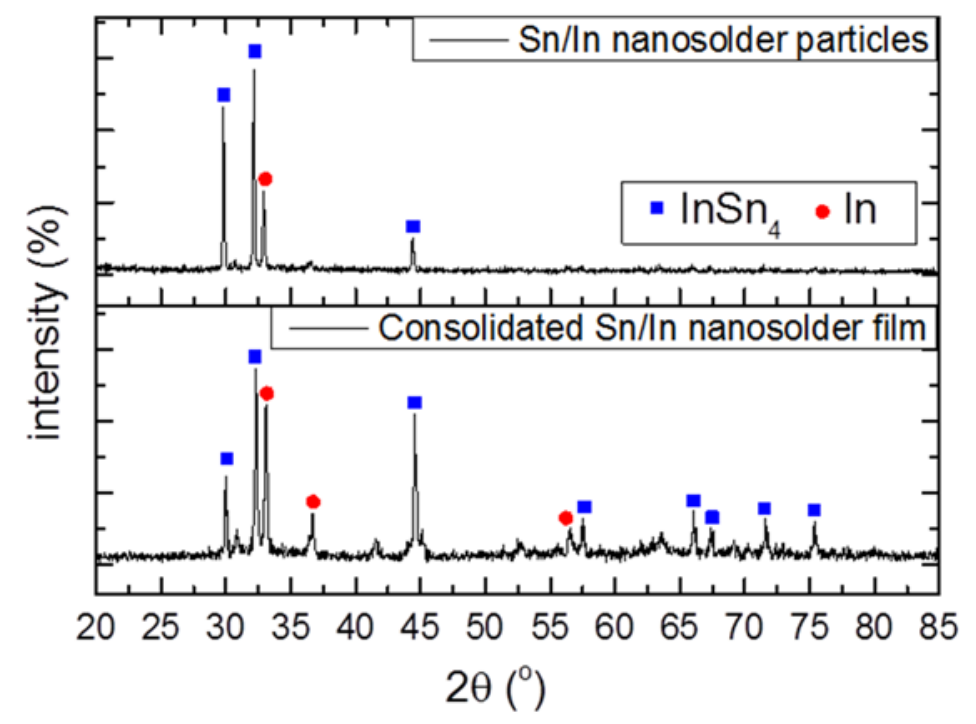

Fig. 5: Comparison of $\mathrm{Sn} / \mathrm{In}$ nanosolders before and after consolidation: XRD results.

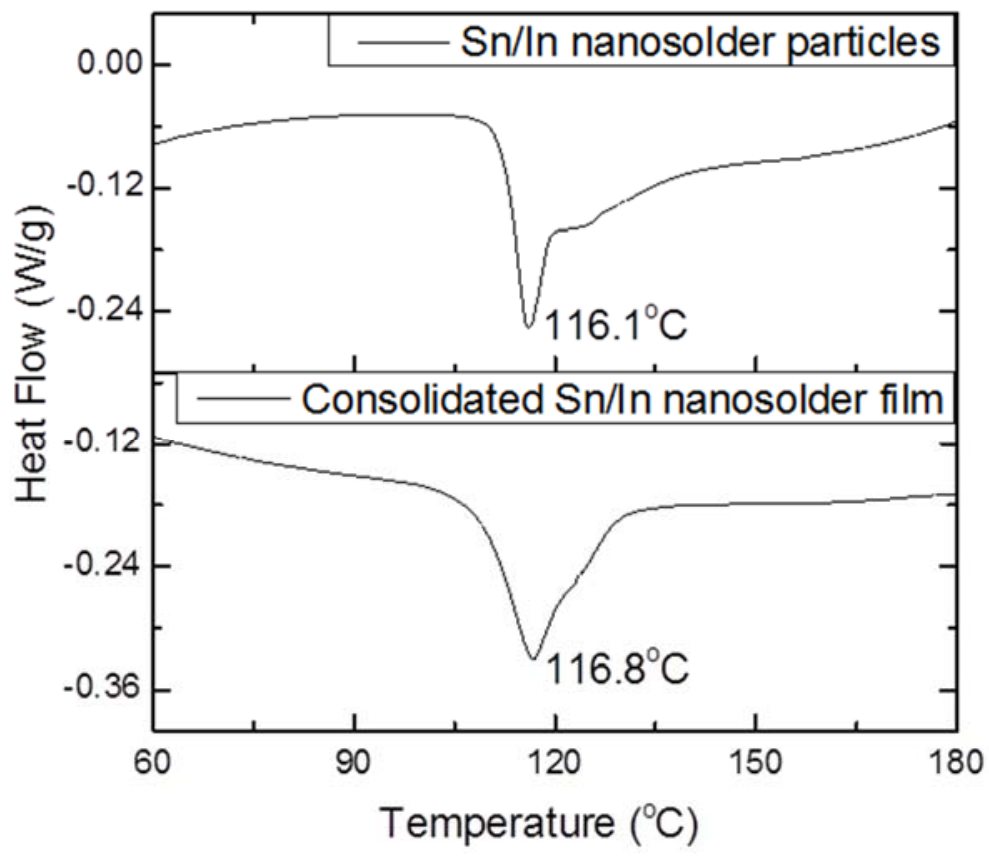

Fig. 6: Comparison of Sn/In nanosolders before and after consolidation: DSC results.

\subsection{IMC and interfacial structure of the Sn/In nanosolder joint between $\mathrm{Cu}-\mathrm{Cu}$ plates}

The specimen formed a solid joint after reflowed by method I under high pressure (100 MPa) for $5 \mathrm{~min}$. In the low pressure joining (method II), heating times of $5 \mathrm{~min}, 15 \mathrm{~min}$, and $30 \mathrm{~min}$ were 
tested. Only with the dwell time of $30 \mathrm{~min}$, a solid solder joint can be formed by method II. Dwell times of $5 \mathrm{~min}$ and $15 \mathrm{~min}$ led to very weak solder joints. Therefore, in the following discussion, method II refers to a low pressure reflow with dwell time of $30 \mathrm{~min}$. Fig. 7 shows the cross section back-scattered electron (BSE) images of the joint interface after reflow with the two joining methods (methods I and II). The layers of $\mathrm{Cu}$, IMC and solder were labeled in the figures accordingly. An IMC layer was formed uniformly at the interface of $\mathrm{Cu}$ and the nanosolder film on the samples formed by both methods. The thickness of the IMC layer was $0.78 \mu \mathrm{m}$ in the sample formed by method I, and $1.95 \mu \mathrm{m}$ in the sample formed by method II. The difference in IMC layer thickness comes from the difference in reflow time and pressure. The longer dwell time (30 $\mathrm{min}$ ) increases the IMC growth rate. In addition, the higher pressure of 100 MPa used in method I helped the densification process during the soldering. The high pressure eliminated some fraction of pores that came from the dissolution of the oxide shell on the nanoparticles. It increased the contact area between the nanosolder particles during the heating and reduced the volume shrinkage effect of nanosolders during solidification, thus speeding up the free surface area reduction. Also, the pressure provided another driving force of joining. Therefore, the sample can be joined in a relatively short time $(5 \mathrm{~min})$, and the IMC layer has been restricted from growing [33-35].
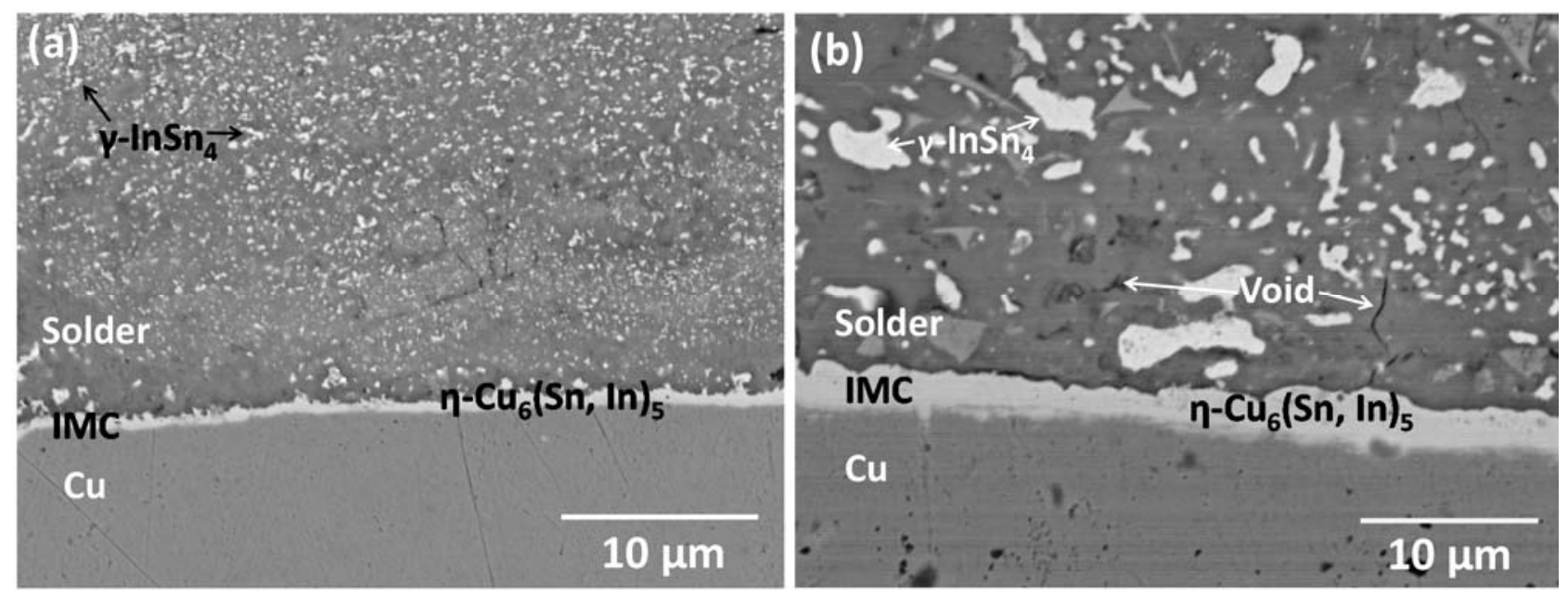

Fig. 7: SEM images of $\mathrm{Sn} / \mathrm{In}$ nanosolder film after reflow under condition (a) method I (100 $\mathrm{MPa}, 5 \mathrm{~min}$ ); (b) method II (low pressure, $30 \mathrm{~min}$ ). 
Table 1 shows the chemical composition of the interfacial structure, which was determined by EDS. The EDS of each region on the samples reflowed by the two methods showed similar results. The elemental composition of the IMC layer (in Table 1) suggests the crystalline structure of the IMC layer to be $\eta-\mathrm{Cu}_{6}(\mathrm{In}, \mathrm{Sn})_{5}$ [36-37]. For both samples, IMC particles (light particles) were randomly distributed in the solder matrix (dark background). Under the method I condition, the light particles were in sub-micron sizes; whereas the light particles formed by method II were relatively larger (up to a few microns). The EDS data suggested that the light particles in both samples consist mainly of $\gamma$ - $\mathrm{InSn}_{4}$, which is from the main alloy in the consolidated Sn/In nanosolder film, and small amount of In. The crystal structure of the solder matrix was suggested to be mainly In in both samples, but more Sn ( 20.9 at\%) was present in the sample joined by method II. The EDS results in Table 1 show that a small amount of $\mathrm{Cu}$ has been dissolved in the solder layer, both in the light particles and the dark solder matrix. It is possible that a ternary compound such as $\mathrm{Cu}_{2} \mathrm{In}_{3} \mathrm{Sn}$ might be formed in these areas [36-37]. Some small dark (black) areas were also observed in the solder layer (marked in Fig. 7b), which were probably voids that were formed during joining. The porosity was estimated by the area fraction of the void by using ImageJ. Almost no voids (under $0.1 \%$ ) were observed in the sample formed by method I (Fig. 7a), and only a very small amount of voids were found ( $0.52 \%)$ in the sample formed by method II (Fig. 7b).

Table 1: Elemental compositions of solder alloys after reflow under method I and method II conditions.

\begin{tabular}{|c|c|c|c|c|c|c|c|c|c|}
\hline \multirow{2}{*}{} & \multicolumn{3}{|c|}{ Intermetallic layer } & \multicolumn{3}{c|}{ Solder matrix (dark) } & \multicolumn{3}{c|}{ Small particles (light) } \\
\cline { 2 - 9 } & $\mathrm{Cu}$ & $\mathrm{Sn}$ & $\mathrm{In}$ & $\mathrm{Cu}$ & $\mathrm{Sn}$ & $\mathrm{In}$ & $\mathrm{Cu}$ & $\mathrm{Sn}$ & $\mathrm{In}$ \\
\hline $\begin{array}{c}\text { Method I } \\
\text { (at\%) }\end{array}$ & 53.9 & 26.4 & 19.7 & 9.8 & 6.3 & 83.9 & 5 & 70.4 & 24.6 \\
\hline $\begin{array}{c}\text { Method II } \\
\text { (at\%) }\end{array}$ & 56.3 & 27.9 & 15.8 & 7.5 & 20.9 & 71.6 & 9.8 & 67.1 & 23.1 \\
\hline
\end{tabular}

The interfacial structure of the $\mathrm{Sn} / \mathrm{In}$ consolidated nanosolder film on $\mathrm{Cu}$ showed some similarity to the results observed by Lee et al. [38], which discussed the effect of In addition on the solder joints formed by $\mathrm{Sn}$ solder on $\mathrm{Cu}$ substrate. In Lee's work, the joint was formed with $\mathrm{Sn} / \mathrm{In}$ 
solder alloys $\left(0,4,8,16 \mathrm{wt} \%\right.$ of In in Sn), reflowed at $250^{\circ} \mathrm{C}$ for $60 \mathrm{~s}$. In the samples with 8 and $16 \mathrm{wt} \%$ In compositions, a scallop shaped IMC phase $\eta_{-} \mathrm{Cu}_{6}(\mathrm{Sn}, \mathrm{In})_{5}$ was formed during the reflow. In our work, an IMC phase of $\eta_{-}-\mathrm{Cu}_{6}(\mathrm{Sn}, \mathrm{In})_{5}$ was also found at the solder joint formed with the consolidated Sn/In nanosolder film. The thickness of the IMC layer was about $4 \mu \mathrm{m}$ in Lee's work while in the present study the IMC layers formed with the consolidated Sn/In nanosolders were only $0.78 \mu \mathrm{m}(100 \mathrm{MPa})$ and $1.95 \mu \mathrm{m}$ (low pressure), respectively, both of which are significantly thinner than the Sn solder with addition of In reported by Lee. Additionally, in Lee's work, micron sized $\eta-\mathrm{Cu}_{6}(\mathrm{Sn}, \mathrm{In})_{5}$ particles formed in the solder matrix were observed, and both the $\gamma$-InSn 4 and $\beta$-Sn phases may also exist in the solder layer [38]. In the present work, although $\gamma$-InSn4 and $\beta$-Sn can also be found in the solder layer of the joint formed by the consolidated sample, n-Cu6(Sn, In)5 particles were not observed. Other than $\mathrm{Sn} / \mathrm{In}$ solders, $\mathrm{SAC}$ solder $(\mathrm{Sn3} .6 \mathrm{Ag} 0.9 \mathrm{Cu})$ has been reported to form a $1.7 \mu \mathrm{m} \mathrm{IMC} \mathrm{layer} \mathrm{of} \eta_{-} \mathrm{Cu}_{6} \mathrm{Sn}_{5}$ on $\mathrm{Cu}$ under a reflow condition of $250{ }^{\circ} \mathrm{C}$ for 5-10 s with $\mathrm{ZnCl}_{2}$ flux [39]. Under the same condition, the thickness of the IMC layer formed with a SAC solder mixed with In and Ce granules $(\mathrm{Sn3} .6 \mathrm{Ag} 0.9 \mathrm{Cu}+1.7 \mathrm{In}+0.3 \mathrm{Ce})$ was decreased to $1 \mu \mathrm{m}$ [39]. Compared with the reports above, the thickness of the IMC layer in the sample formed by method I (high pressure) in this study was significantly thinner than the reported results. Even the sample formed by method II with a much longer reflow time (30 min) had a comparable result of the IMC thickness with the reported work for SAC solders. The observation indicated that nanosolder had a significant effect in controlling the formation and growth of the IMC layer, and that pressure is critical in the IMC thickness control as well.

\subsection{Aging effect on IMC growth}

The aging tests were carried out at $100{ }^{\circ} \mathrm{C}$ for two extended time durations, $50 \mathrm{~h}$ and $100 \mathrm{~h}$. The cross section BSE images of the specimens under the two joining conditions were shown in Fig. 8 and Fig. 9. Table 2 and 3 list the chemical compositions of different regions of the reflow solder after the aging tests. The results in Table 2 are interpreted in Fig. 10 to show the trend of the composition change along aging times in different regions of the solder joints. From Fig. 10a, the elements almost remained the same after 100 hours aging (except a little fluctuation at $50 \mathrm{~h}$ ), indicating that the IMC layer retained the same crystal structure of $\eta-\mathrm{Cu}_{6}(\mathrm{Sn}, \mathrm{In})_{5}$ as the freshly joined sample. In both methods, the IMC layer thickness of the samples increased with aging 
time (Fig. 8 and 9). In the sample joined by method I, the IMC layer thickness increased from $0.76 \mu \mathrm{m}$ (before aging) to $1.01 \mu \mathrm{m}$ at $50 \mathrm{~h}$ and $1.15 \mu \mathrm{m}$ at $100 \mathrm{~h}$; for method II, the IMC layer thickness increased from an initial value of $1.95 \mu \mathrm{m}$ to $4.68 \mu \mathrm{m}$ at $50 \mathrm{~h}$ and $5.73 \mu \mathrm{m}$ at $100 \mathrm{~h}$ (see Fig. 11). In both cases, the thickness of the IMC layer followed a linear relationship with the square root of the aging time. The linear relationship revealed that the growth of IMC was diffusion-limited [40]. However, the slopes were different for the two fitting lines in Fig. 11, indicating that the rates of IMC layer growth were different for the samples soldered by the different methods. The sample that formed by method I had a significantly lower thickening rate of the IMC layer. This is contrasted by the much larger amount of the $\mathrm{InSn}_{4}$ particles that were formed in the solder layer from the sample joined by method I (Fig. 7a and 8), which suggests that in the method I sample, larger amounts of the Sn and In required for IMC layer growth were consumed in the formation of the InSn 4 particles in the solder layer. In addition, the fine $\mathrm{InSn}_{4}$ particles in the solder layer of the sample formed by method I provided a large interfacial area between particles and the In matrix where vacancies may be absorbed, particularly under the high pressure (method I), thereby restricting the diffusion.
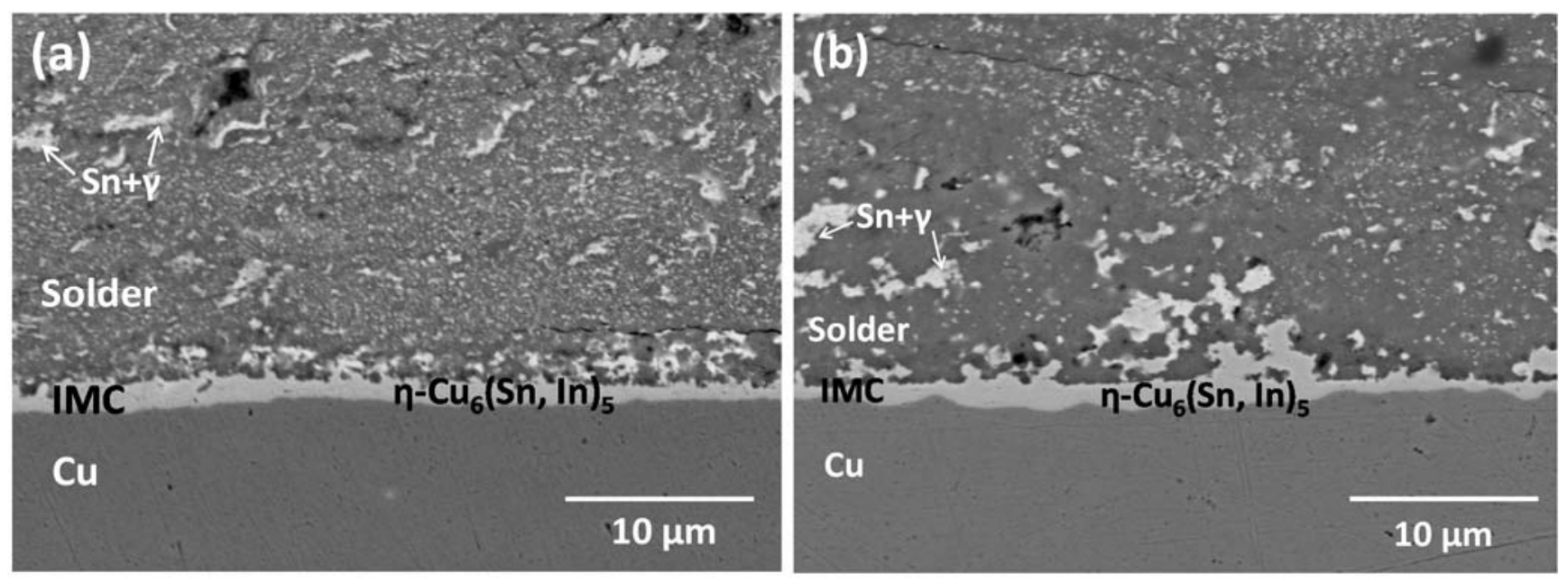

Fig. 8: SEM images of the cross-section of solder joints formed by method I after aging at $100{ }^{\circ} \mathrm{C}$ for (a) $50 \mathrm{~h}$, (b) $100 \mathrm{~h}$. 

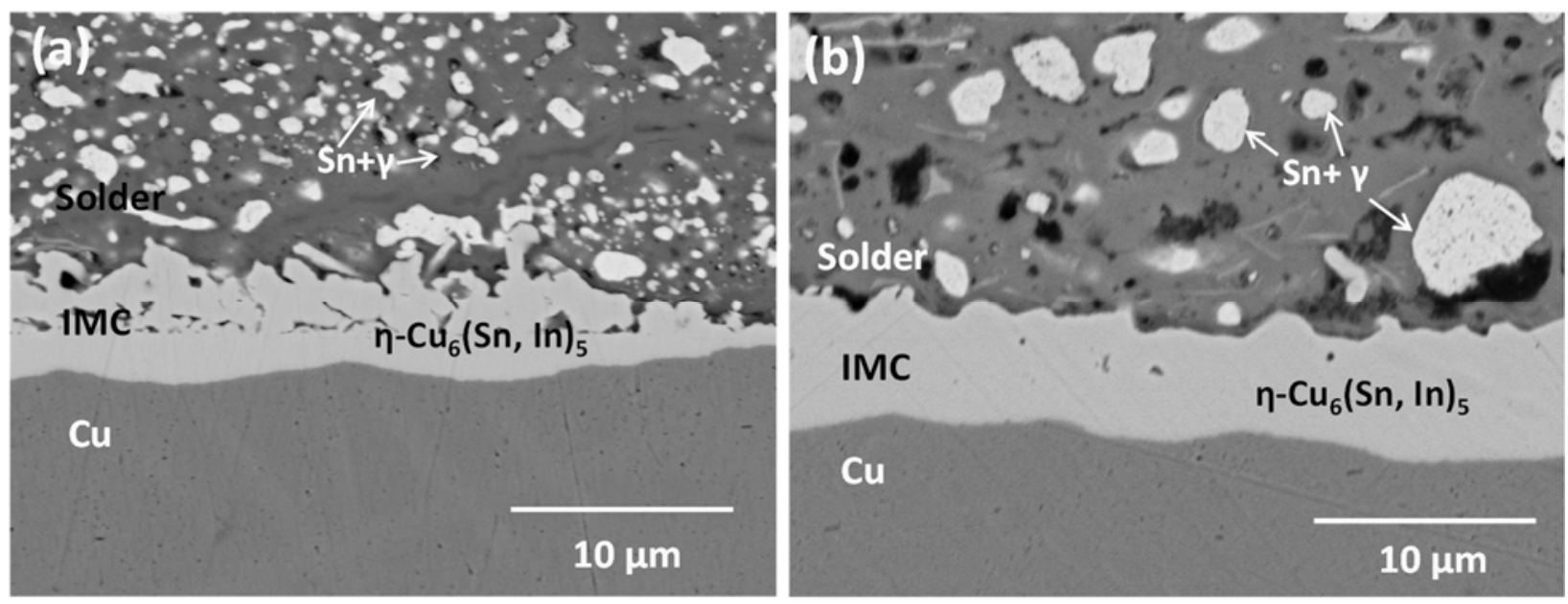

Fig. 9: SEM images of the cross-section of solder joints formed by method II after aging at $100{ }^{\circ} \mathrm{C}$ for (a) $50 \mathrm{~h}$, (b) $100 \mathrm{~h}$.

As the aging time extended, void formation was observed in both samples, mainly formed at the $\gamma$-matrix interface. No voids were observed at the IMC-Cu interface. Also, based on the observation of cross sectional SEM images (Fig. 8 and 9) and the EDS results (Tables 2 and 3) of the IMC layer, the $\eta-\mathrm{Cu}_{6}(\mathrm{Sn}, \mathrm{In})_{5}$ was the only phase present in the IMC layer, and no $\mathrm{Cu}_{3}(\mathrm{Sn}, \mathrm{In})$ was observed. The above observations in the present study are different from previous studies on Sn-based solders [41-45], in which morphological change of $\eta-\mathrm{Cu}_{6}(\mathrm{Sn}, \mathrm{In})_{5}$ was found, but no void formation in the solder layer during aging tests. In the previous studies, $\mathrm{Cu}_{3}(\mathrm{Sn}$, In) would form between the $\eta-\mathrm{Cu}_{6}(\mathrm{Sn}, \mathrm{In})_{5}$ layer and the $\mathrm{Cu}$ layer. Kirkendall voids were only found in the solder joints subjected to prolonged aging (over $300 \mathrm{~h}$ ) at the aging temperature at/above $150^{\circ} \mathrm{C}$ [41-45]. The absence of $\mathrm{Cu}_{3}(\mathrm{In}, \mathrm{Sn})$ and void at the IMC-Cu interface in the samples made by method I and II in the present study might be due to the lower aging temperature and shorter aging time.

Comparing the samples that were joined by the two methods, the Sn-rich light particles in the solder layer coarsened into larger particles in both samples during the aging process (Fig. 8 and 9). At aging times of $50 \mathrm{~h}$ and $100 \mathrm{~h}$, the atomic percents of $\mathrm{Sn}$ in the light particles of the samples joined by method I are 89.8 at\% and 89.8 at\% (Fig. 10c), and in the sample joined by method II are 77.8 at\% and 85.7 at\% (Table. 3). This suggests that the Sn rich light particles mainly consist of $\mathrm{Sn}$, and might contain $\gamma$-InSn 4 . At the same time, the elemental ratio of $\mathrm{Sn}$ in the solder matrix dropped from $6.3 \mathrm{at} \%$ (before aging) to 2 at\% (aging $100 \mathrm{~h}$ ) in method I (Fig. 
10b), and from 20.9 at\% (before aging) to 4.7 at\% (aging $100 \mathrm{~h}$ ) in method II (Table 3), indicating the precipitation of Sn from the solder matrix (Fig. 10b). The main crystal structure of the solder matrix was In after $100 \mathrm{~h}$ aging in the samples formed by both methods. From Fig. 8 and 9, the void coarsening during aging in the samples joined by method I was much less than the one formed by method II. The porosity increased from less than $0.1 \%$ before the aging to $0.18 \%$ after $50 \mathrm{~h}$, and $0.77 \%$ after $100 \mathrm{~h}$ in the sample joined by method I. Whereas in the sample joined by method II, the porosity increased from the initial $0.52 \%$ to $1.95 \%$ at $50 \mathrm{~h}$, and $3.07 \%$ after $100 \mathrm{~h}$. It is possible that in method I, a large amount of vacancies were absorbed by the large interfacial areas between the InSn4 particles and In matrix in the joining step under the high pressure (100MPa), therefore during the aging, only a small amount of void accumulated into Kirkendall void that was observed in Fig. 8. Overall, the porosities in both samples are relatively small. Further analysis is needed to get a better understanding of the void formation and growth.

Table 2: Elemental compositions of solder alloys after aging for $50 \mathrm{~h}$ and $100 \mathrm{~h}$ under the method I reflow condition.

\begin{tabular}{|c|c|c|c|c|c|c|c|c|c|}
\hline \multirow{2}{*}{} & \multicolumn{3}{|c|}{ Intermetallic layer } & \multicolumn{3}{c|}{ Solder matrix (dark) } & \multicolumn{3}{c|}{ Small particles (light) } \\
\cline { 2 - 10 } & $\mathbf{C u}$ & Sn & In & Cu & Sn & In & Cu & Sn & In \\
\hline $\begin{array}{c}50 \mathrm{~h} \\
(\mathrm{at} \%)\end{array}$ & 51.9 & 37 & 11.1 & 8.6 & 15.4 & 76 & 4.7 & 89.8 & 5.5 \\
\hline $\begin{array}{c}100 \mathrm{~h} \\
(\mathrm{at} \%)\end{array}$ & 56.6 & 26.7 & 16.7 & 8.2 & 2 & 89.8 & 5.2 & 89.8 & 5 \\
\hline
\end{tabular}

Table 3: Elemental compositions of solder alloys after aging for $50 \mathrm{~h}$ and $100 \mathrm{~h}$ under the method II reflow condition.

\begin{tabular}{|c|c|c|c|c|c|c|c|c|c|}
\hline & \multicolumn{3}{|c|}{ Intermetallic layer } & \multicolumn{3}{c|}{ Solder matrix (dark) } & \multicolumn{3}{c|}{ Small particles (light) } \\
\cline { 2 - 10 } & $\mathbf{C u}$ & Sn & In & Cu & Sn & In & Cu & Sn & In \\
\hline $\begin{array}{c}50 \mathrm{~h} \\
(\mathrm{at} \%)\end{array}$ & 51 & 34.8 & 14.2 & 5.7 & 4.2 & 90.1 & 4.8 & 77.8 & 17.4 \\
\hline $\begin{array}{c}100 \mathrm{~h} \\
(\mathrm{at} \%)\end{array}$ & 58 & 26.1 & 16.9 & 7.5 & 4.7 & 87.9 & 5.8 & 85.7 & 8.4 \\
\hline
\end{tabular}



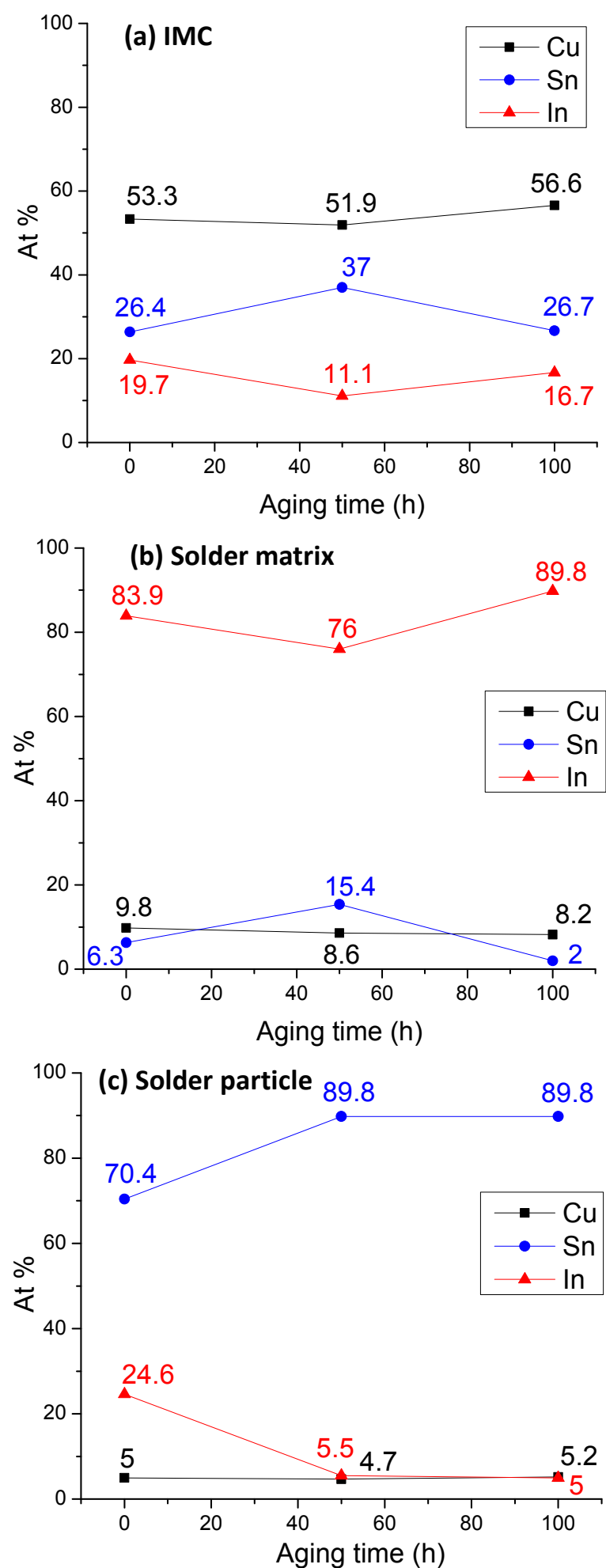

Fig. 10: Elemental compositions of solder alloys after aging for $50 \mathrm{~h}$ and $100 \mathrm{~h}$ under the method I reflow condition. 


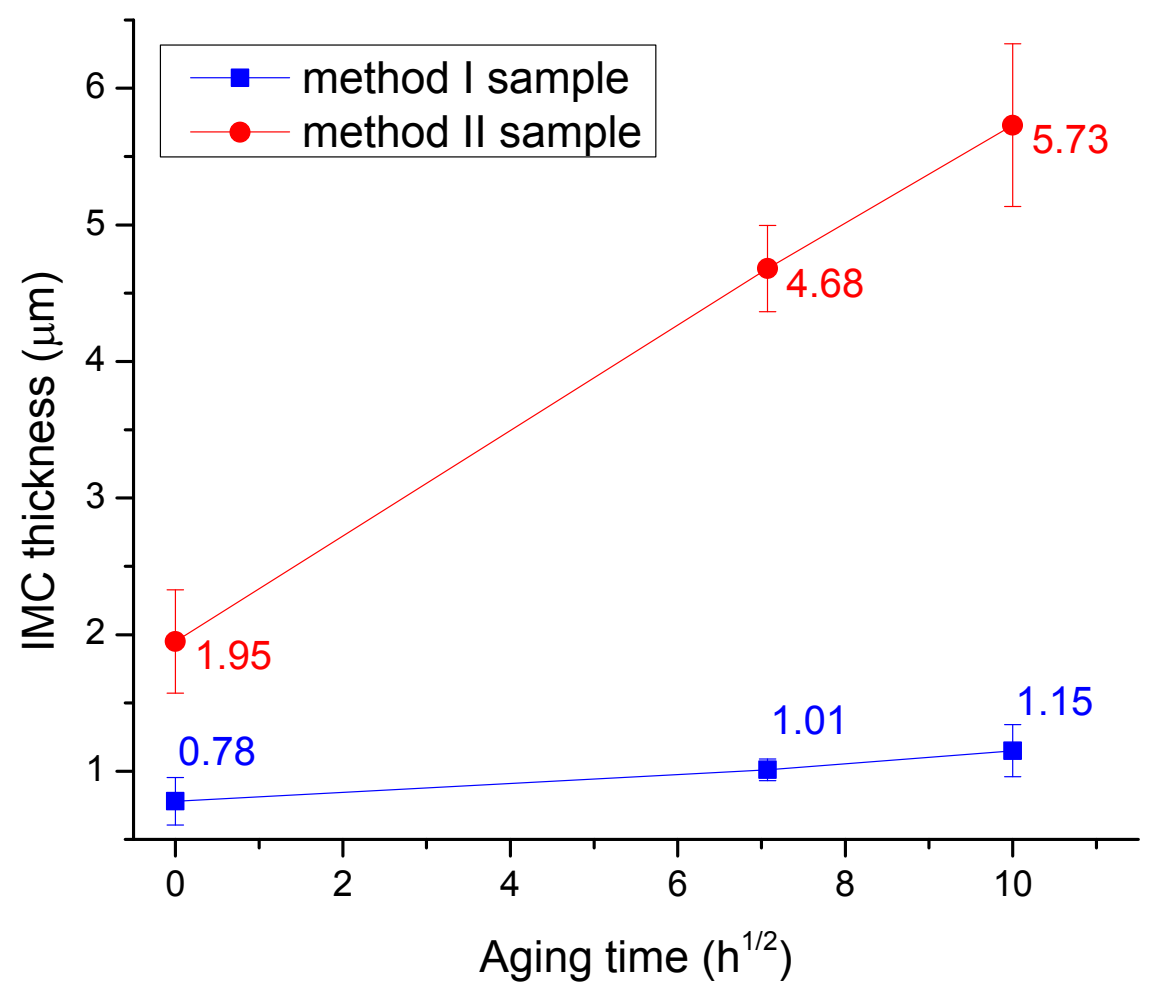

Fig. 11: Thickness of the IMC layers as the aging time extended.

\subsection{Tensile strength of the solder joint}

The strength of the solder joint formed by method I was determined by a pull test, in the manner illustrated in the figure inserted in Fig. 12. Fig. 12 shows the stress-displacement curve obtained in the pull test. The joint strength, defined as the stress at fracture, is $7.76 \mathrm{MPa}$. Fig. 13 shows the fracture surface of the solder joint between the two $\mathrm{Cu}$ plates that were jointed, where it can be seen that the fracture occurred primarily through the solder over the circular area where the solder joint was formed. The circular area of $29.1 \mathrm{~mm}^{2}$ in Fig. 13 was defined to be the fracture area to calculate the tensile strength. The strength of the joint formed by consolidated $\mathrm{Sn} / \mathrm{In}$ nanosolder film is comparable to the strengths reported on $\mathrm{In}_{52} \mathrm{Sn}_{48}$ solder used in MEMS, which were $8.11 \mathrm{MPa}$ for a joint with $1.96 \mathrm{~mm}^{2}$ fracture surface and $6.66 \mathrm{MPa}$ for a joint with a fracture surface of $4.875 \mathrm{~mm}^{2}$ [46]. Thus, the $\mathrm{Sn} / \mathrm{In}$ joint formed between $\mathrm{Cu}$ plates by the high pressure method (method I) had an acceptable strength. 


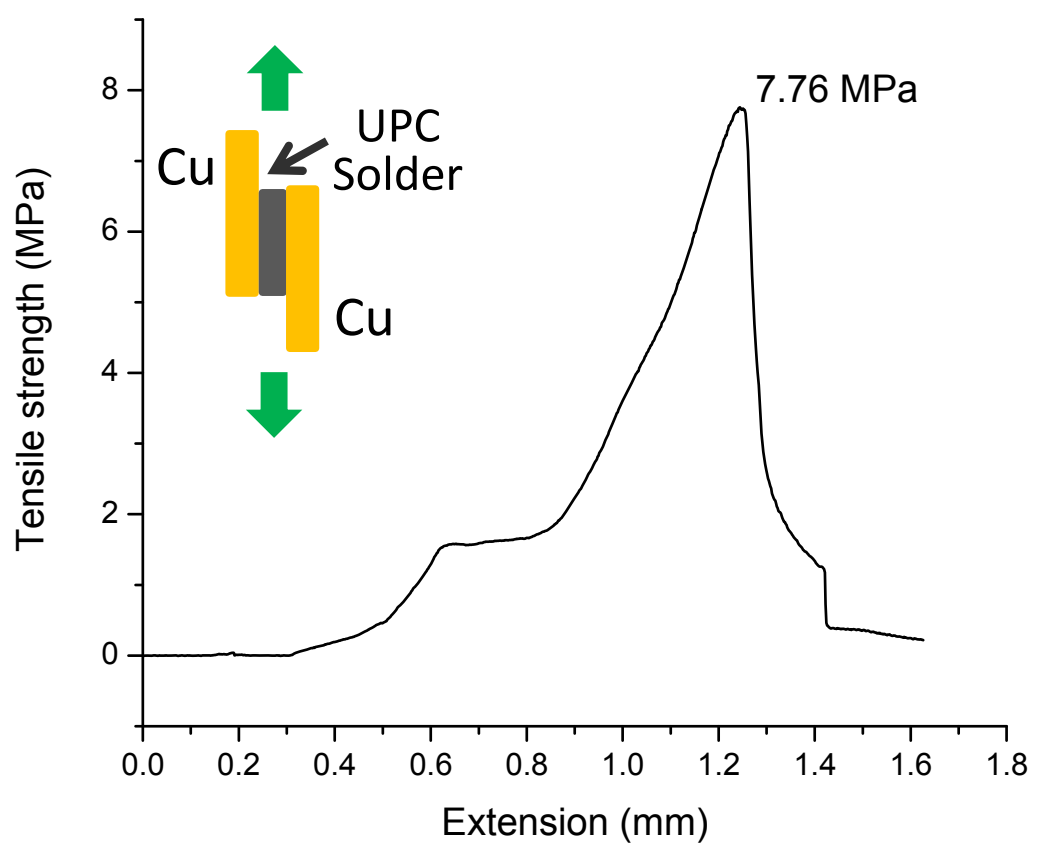

Fig. 12: Pull test results of the joint formed by method I.

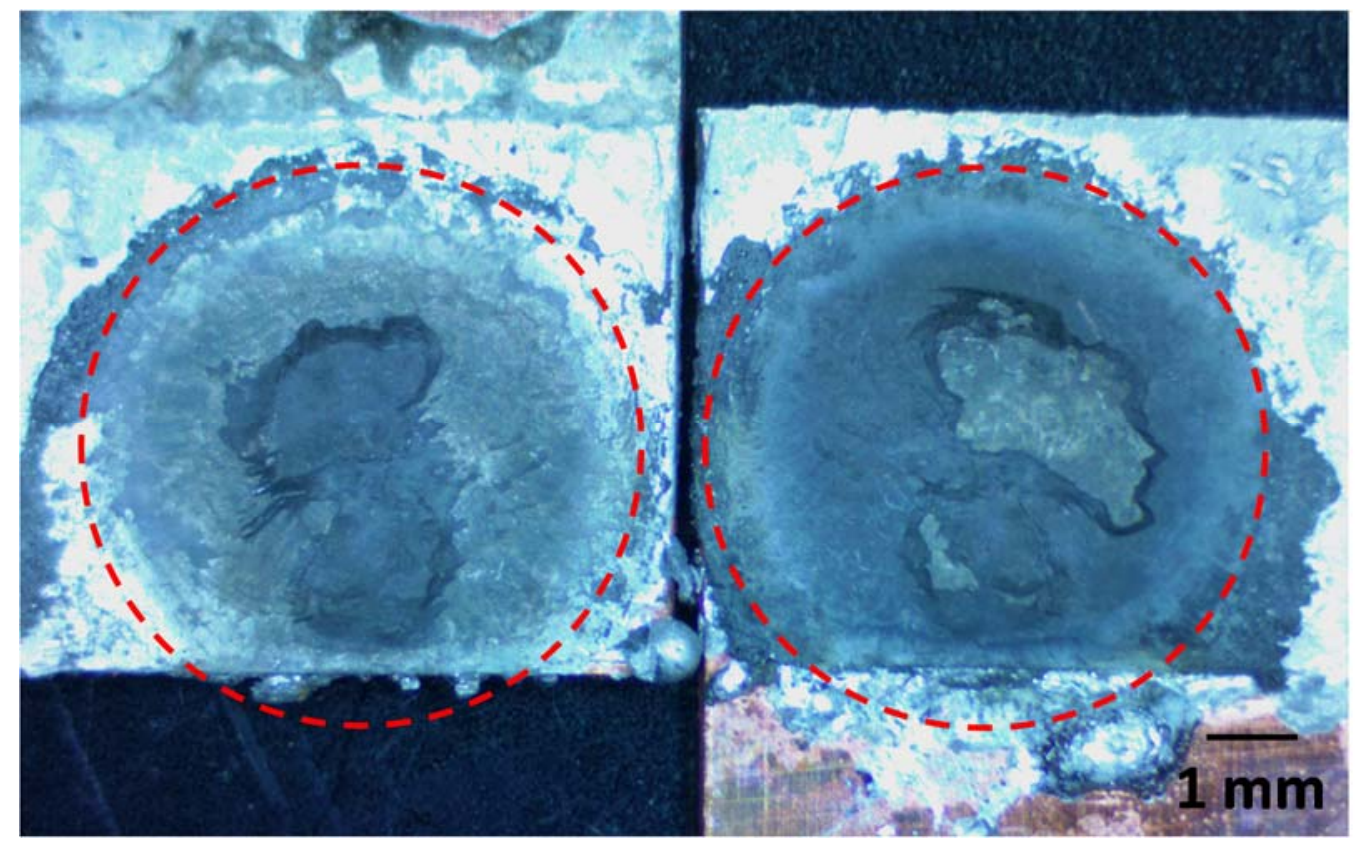

Fig. 13: Fractural surface of the solder joint formed by method I after the pull test. 


\section{Conclusions}

$\mathrm{Sn} / \mathrm{In}$ nanosolder particles have been consolidated into low melting temperature nanosolder films through the UPC method. The consolidated nanosolder film achieved full densification and kept the same structure and properties as the original nanoparticles. With the assistance of a flux, consolidated $\mathrm{Sn} / \mathrm{In}$ nanosolder film successfully soldered two $\mathrm{Cu}$ plates together under two joining conditions. Comparing the two soldering methods, the sample formed under high pressure with less heating time showed a significant effect of restricting the growth of IMC layer thickness and voids coarsening. The IMC study and aging test indicated that the IMC growth is diffusion-controlled. Voids were mainly found at the $\gamma$-matrix interface in the solder matrix and the amont of voids formed were relatively small. Pull test showed that the mechanical property of the solder joint formed by the UPC consolidated $\mathrm{Sn} / \mathrm{In}$ nanosolder films is comparable to the previously reported work on $\mathrm{Sn} / \mathrm{In}$ solders. The results indicate that the $\mathrm{Sn} / \mathrm{In}$ nanosolder film pre-consolidated by UPC can serve as a new approach for low temperature $\mathrm{Cu}-\mathrm{Cu}$ joining and Cu-based surface mounting applications.

\section{Acknowledgements}

Financial supports from the National Science Foundation (CMMI-1031532 and CMMI-1234532) are greatly appreciated. Also, the authors thank Dr. Zhequn Huang for her help in $\mathrm{Cu}-\mathrm{Cu}$ joining experiment. 


\section{References}

1. Y. Zhou, Microjoining and Nanojoining, Woodhead Publishing, 2008.

2. C. L. Bauer, G.G. Lessmann, Metal-Joining Methods, Annu. Rev. Mater. Sci., 6 (1976), $361-387$.

3. Y Zhou, A Hu, M I Khan, W Wu, B Tam, M Yavuz, Recent progress in micro and nanojoining, J. Phys. Conf. Ser., 165 (2009), 012012.

4. Z. Mei, F. Hua, J. Glazer, Low Temperature Soldering, Electronics Manufacturing Technology Symposium, IEEE/CPMT Int. 21st, 1997, 463-476.

5. C. Carsac, J. Uner, M. Theriault, Inert Soldering With Lead-Free Alloys: Review And Evaluation, IPC SMEMA Council APEXSM, 200.1 (2001).

6. J. Glazer, Microstructure and mechanical properties of Pb-free solder alloys for low-cost electronic assembly: A review, J. Electron. Mater., 23 (1994), 693-700.

7. W. Wong, A. Salleo, Flexible Electronics: Materials and Applications, Springer, 2009.

8. Kang, H., Jung, S., Jeong, S., Kim, G., Lee, K, Polymer-metal hybrid transparent electrodes for flexible electronics, Nat. Commun., $6 \quad$ (2015), 6503. doi:10.1038/ncomms 7503

9. Z. Liu, J. Xu, D. Chen, G. Shen, Flexible electronics based on inorganic nanowires, Chem. Soc. Rev., 44 (2015), 161-192.

10. A. Hu, J. Y. Guo, H. Alarifi, G. Patane, Y. Zhou, G. Compagnini, C. X. Xu, Low temperature sintering of Ag nanoparticles for flexible electronics packaging, Appl. Phys. Lett. 97 (2010), 153117.

11. A. Sazonov, D. Striakhilev, Czang-Ho Lee; A. Nathan, Low-Temperature Materials and Thin Film Transistors for Flexible Electronics, Proc. IEEE, 93 (2005), 1420-1428.

12. I. Park, S. H. Ko, H. Pan, C. P. Grigoropoulos, A. P. Pisano, J. M. J. Fréchet, E.-S. Lee, J.-H. Jeong, Nanoscale Patterning and Electronics on Flexible Substrate by Direct Nanoimprinting of Metallic Nanoparticles, Adv. Mater., 20 (2008), 489-496.

13. A. Nathan, B. R. Chalamala, Special Issue on Flexible Electronics Technology, Part 1: Systems and Applications, Proc. IEEE, 93 (2005), 1235 - 1238.

14. W. A. MacDonald, M. K. Looney, D. MacKerron, R. Eveson, R. Adam, K. Hashimoto, K. Rakos, Latest advances in substrates for flexible electronics, J. Soc. Inf. Disp., 15 (2007), 1075-1083.

15. B. D. Gates, Flexible Electronics, Science, 323 (2009), 1566-1567.

16. S. Jang, Y. Seo, J. Choi, T. Kim, J. Cho, S. Kim, D. Kim, Sintering of inkjet printed copper nanoparticles for flexible electronics, Scripta Mater., 62 (2010), 258-261. 
17. I. Cheng, S. Wagner, Overview of Flexible Electronics Technology, Electron. Mater. Sci. Tech., 11 (2009), 1-28.

18. S.H. Kim; M.J. Son, V.L. Nguyen, T. S. Lim, D. Y. Yang, M. H. Kim, K.B. Kim, Y.J. Kim, J.H. Lee, Y.D. Kim, I. Kim, T. M. Lee, Y. J. Kim, S. Yang, Preparation of Property-Controlled Bi-Based Solder Powders by a Ball-Milling Process. Metals, 6 (2016), 74.

19. J. Liu, G. Zhang, Z. Wang, J. Ma, K. Suganuma, Thermal property, wettability and interfacial characterization of novel $\mathrm{Sn}-\mathrm{Zn}-\mathrm{Bi}-\mathrm{In}$ alloys as low-temperature lead-free solders, Mater. Design, 84 (2015), 331-339.

20. K. Kanlayasiri, T. Ariga, Physical properties of Sn58Bi-xNi lead-free solder and its interfacial reaction with copper substrate, Mater. Design, 86 (2015), 371-378.

21. E. E. M. Noor, H. Zuhailawati, O. Radzali. Low temperature In-Bi-Zn solder alloy on copper substrate, J. Mater. Sci. Mater. Electron. 27.2 (2016), 1408-1415.

22. F. Frongia, M. Pilloni, A. Scano, A. Ardu, C. Cannas, A. Musinu, G. Borzone, S. Delsante, R. Novakovic, G. Ennas, Synthesis and melting behavior of Bi, Sn and Sn-Bi nanostructured alloy, J. Alloys Compd., 63 (2015), 7-14.

23. R. M. Panas, M. L. Culpepper, Engineering Electrical Interfaces to Silicon via Indium Solder, IEEE Trans. Electron. Devices, 62.6 (2015), 1977-1983.

24. X. Chen, F. Xue, J. Zhou, Y.Yao, Effect of In on microstructure, thermodynamic characteristic and mechanical properties of Sn-Bi based lead-free solder, J. Alloys Compd., 633 (2015), 377-383.

25. X. Hu, Y. Li, Y. Liu, Z. Min, Developments of high strength Bi-containing Sn0.7Cu leadfree solder alloys prepared by directional solidification, J. Alloys Compd., 625 (2015), 241-250.

26. Z. Mei, H.A. Holder, H.A. Vander Plas, Low-Temperature Solders, J. Hewlett-Packard, 47 (1996), 91 - 98.

27. D. Erdeniz, T. Ando, Fabrication of micro/nano structured aluminum-nickel energetic composites by means of ultrasonic powder consolidation, Int. J. Mater. 104.4 (2013), 387-391.

28. S. Gheybi Hashemabad, Z. Gu, T. Ando, Flux-less direct soldering of aluminum by ultrasonic surface activation, J. Mater. Process. Technol., 233 (2016), 135-14.

29. Z. Gu, Q. Cui, J. Chen, J. Buckley, T. Ando, D. Erdeniz, P. Wong, A. Hadjiafxenti, P. Epaminonda, I. E. Gunduz, C. Rebholz, C. C. Doumanidis, Fabrication, characterization and applications of novel nanoheater structures, Surf. Coat. Tech., 215 (2013), 493-502. 
30. S. Gheybi Hashemabad, T. Ando, Ignition Characteristics of Hybrid Al-Ni-Fe2O3 and Al-Ni-CuO Reactive Composites Fabricated by Ultrasonic Powder, Combust. Flame, 162 (2015), pp. 1144-1152.

31. L. Brown, Cost-Effective Manufacturing: Joining of Copper and Copper Alloys, Copper Development Association, CDA Publication No. 98, 1994.

32. Y. Shu, K. Rajathurai, F. Gao, Q. Cui, Z. Gu. Synthesis and Thermal Properties of Low Melting Temperature Tin/Indium (Sn/In) Lead-free Nanosolders and Their Melting Behavior in a Vapor Flux, J. Alloys Compd., 626 (2015), 391-400.

33. Z. Zhang, G. Lu, Pressure-Assisted Low-Temperature Sintering of Silver Paste as an Alternative Die-Attach Solution to Solder Reflow, IEEE Trans. Electron. Packag. Manuf. 25 (2002), 279-283.

34. M. Knoerr, A. Schletz, Power semiconductor joining through sintering of silver nanoparticles: Evaluation of influence of parameters time, temperature and pressure on density, strength and reliability, CIPS, 2010 6th International Conference on, Nuremberg, 2010, 1-6.

35. L. Ding, R. L. Davidchack, J. Pan, A molecular dynamics study of sintering between nanoparticles, Comput. Mater. Sci, 45 (2009), 247-256.

36. T. Velikanova, M. Turchanin, O. Fabrichnaya, Copper-Indium-Tin, Ternary Alloy Systems: Phase Diagrams, Crystallographic and Thermodynamic Data critically evaluated by MSIT ${ }^{\circledR} \cdot$ Non-Ferrous Metal Systems. Part 3.

37. X. J. Liu, H. S. Liu, I. Ohnuma, R. Kainuma, K. Ishida, S. Itabashi, K. kameda, K. Yamaguchi, Experimental determination and thermodynamic calculation of the phase equilibria in the Cu-In-Sn system, J. Electron. Mater. 30 (2011), 1093-1103.

38. K. Lee, K, Kim, K, Suganuma, Influence of indium addition on electromigration behaviour of solder joint, J. Mater. Res., 26 (2011), 2624-2631.

39. H. Fallahi, M.S. Nurulakmal, A. Fallahi Arezodar, J. Abdullah, Effect of iron and indium on IMC formation and mechanical properties of lead-free solder, Mater. Sci. Eng., A, 553 (2012), 22-31.

40. W. Peng, E. Monlevade, M. E. Marques, Effect of thermal aging on the interfacial structure of SnAgCu solder joints on Cu, Microelectron. Reliab., 47 (2007), 2161-2168,

41. X. Deng, G. Piotrowski, J.J. Williams, N. Chawla, Influence of Initial Morphology and Thickness of $\mathrm{Cu}_{6} \mathrm{Sn}_{5}$ and $\mathrm{Cu}_{3} \mathrm{Sn}$ Intermetallics on Growth and Evolution during Thermal Aging of Sn-Ag Solder/Cu Joints, J. Electron. Mater., 32 (2003), 1403-1413.

42. E. Hodúlová, M. Palcut, E. Lechovič, B. Šimeková, K. Ulrich, Kinetics of intermetallic phase formation at the interface of $\mathrm{Sn}-\mathrm{Ag}-\mathrm{Cu}-\mathrm{X}(X=\mathrm{Bi}$, In) solders with $\mathrm{Cu}$ substrate, J. Alloys Compd., 509 (2011), 7052-7059. 
43. J. Yu, J.Y. Kim, Effects of residual S on Kirkendall void formation at $\mathrm{Cu} / \mathrm{Sn}-3.5 \mathrm{Ag}$ solder joints, Acta Mater., 56 (2008), 5514-5523.

44. Z. Mei, M. Ahmad, M. Hu and G. Ramakrishna, Kirkendall voids at Cu/solder interface and their effects on solder joint reliability, ECTC '05, 1 (2005), 415-420.

45. A. T. Wu, M. Chen, C. Siao, The Effects of Solid-State Aging on the Intermetallic Compounds of Sn-Ag-Bi-In Solders on Cu Substrates, J. Electron. Mater., 38 (2009), 252256.

46. J. Cheong, A. Goyal, S. Tadigadapa, C. Rahn, Reliable bonding using indium-based solders, Proceedings of SPIE, Reliability, Testing, and Characterization of MEMS/MOEMS III, 5343 (2004), 114-120. 


\section{Graphical Abstract}

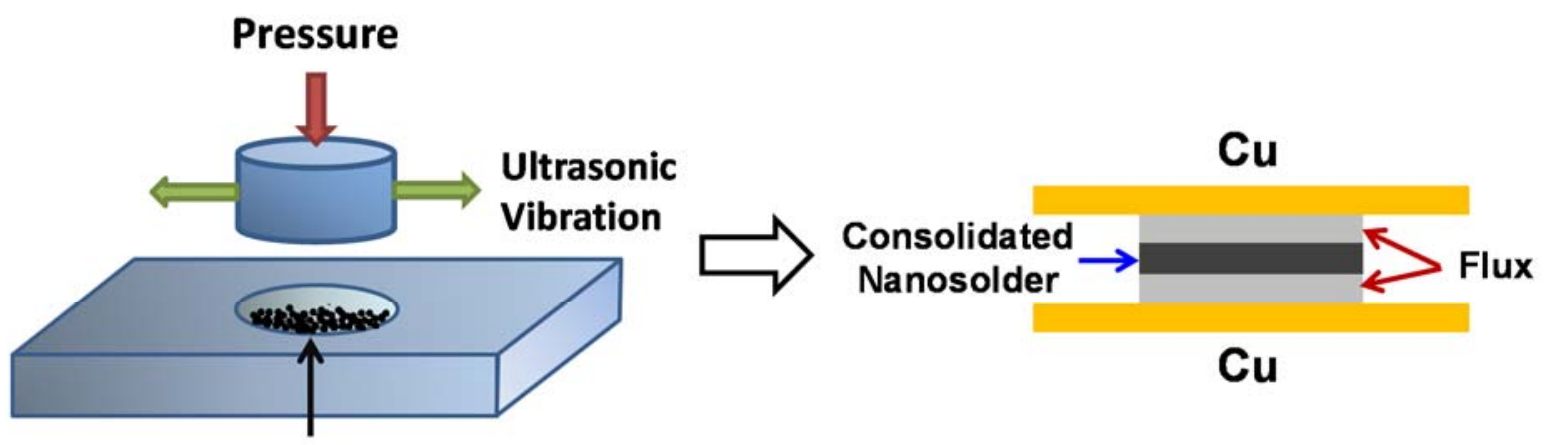

Sn/In Nanosolder Particles

Ultrasonic Powder Consolidation (UPC)

Cu-Cu joining with UPC consolidated nanosolder film 